\title{
The Brazilian neuroinfection meeting 2013
}

\section{Encontro brasileiro de neuroinfecção 2013}

Ronaldo Abraham

Medicine Department, Taubaté University, Taubaté SP, Brazil.

Correspondence

Ronaldo Abraham

Rua Dr. Souza Alves 35

12020-030 Taubaté SP - Brasil

E-mail:rnabraham@uol.com.br
7 he Brazilian neuroinfection meeting is a traditional event held every two years under the sponsorship of Academia Brasileira de Neurologia (ABN). As from the late 80s it has become independent from the Neurology Brazilian Congress. Except for a few cases, the event has been mainly held at the Centro de Convenções Rebouças, located in the city of São Paulo.

This year of 2013 this meeting will have the strength of two ABN scientific departments, the neuroinfection and the cerebrospinal fluid. In an unprecedented way, it was proposed the edition of a special issue of Arquivos de Neuro-Psiquiatria, the Official Journal of the ABN, with the content of its lectures.

Doing science and producing knowledge has not been easy task in our country. Infectious diseases remain an extremely important issue due to their high occurrence rate in Brazil; usually their neurological expression represents the most severe forms of these diseases. Some of them are clearly neglected by authorities, turning into real challenge for those who take care of patients affected by them.

It was not easy to find supporters of the edition of this issue, so I would like to sincerely thank the pharmaceutical industries that believed in this project.

In my personal name I would like to thank the editors of this periodic for the confidence in letting this edition under my responsibility. I hope you like it, so as to assure the well-deserved reputation of the Arquivos de Neuro-Psiquiatria.

Finally, I would like to say that it was not easy to find a date to hold this meeting at Centro de Convenções Rebouças. Incidentally (or not) it was scheduled exactly for the day we celebrate the birthday of Professor Antonio Spina-França Netto, pioneer in neuroinfection in our country and emeritus editor of this periodic, to whom I dedicate this special issue of Arquivos de Neuro-Psiquiatria. 